\title{
Aplicação de indicadores de fragilidade do sistema de natureza ambiental na bacia hidrográfica do rio Cintra-MG
}

\author{
Application of indicators of weakness in the system of environmental nature in watershed stream Cintra-MG \\ Valdevino José dos Santos Júnior', Carolina Oliveira Santos² \\ ' Engenheiro Ambiental - Faculdade de Ciências Exatas e Tecnológicas Santo Agostinho - Montes Claros/MG. \\ ${ }^{2}$ Engenheira Química - Faculdade de Ciências Exatas e Tecnológicas Santo Agostinho - Montes Claros/MG.
}

\begin{abstract}
Resumo
Os problemas decorrentes da urbanização desordenada são devido à inexistência de políticas de desenvolvimento urbano, como os planos diretores (RIBEIRO e ROOKE, 2010). Neste contexto, o objetivo deste estudo é utilizar Indicadores de Fragilidade do Sistema (IFS) de natureza ambiental e aplicá-los na bacia hidrográfica do rio Cintra em Montes Claros-MG, com intuito de identificar os fatores que interferem no sistema de drenagem pluvial urbano bem como o grau de fragilidade da bacia. Para isto, foram selecionados três pontos de estudo (PEs) na bacia, a citar: nascente, médio curso e foz do rio, para a aplicação dos indicadores de fragilidade do sistema de natureza ambiental. Na bacia identificou-se processos erosivos, interações negativas dos sistemas de drenagem com efluentes domésticos, resíduos sólidos, dentre outros. Os Índices Geral de Fragilidade (IGFs) encontrados foram 57, 49 e 72, respectivamente para a nascente, médio curso e foz do rio, caracterizando alto grau fragilidade sob o aspecto ambiental, variando entre Forte a Muito Forte. Conclui-se que a utilização de indicadores de fragilidade é de suma importância para a gestão pública, sobretudo como uma ferramenta para a identificação de fatores intervenientes e de fragilidade dos sistemas de drenagem pluvial urbano.
\end{abstract}

Palavras-chaves: Drenagem Urbana; avaliação ambiental; percepção ambiental.

\begin{abstract}
The problems arising from unplanned urbanization are due to the lack of urban development policies, such as master plans (RIBEIRO e ROOKE, 2010). The use of indicators constitutes an instrument of great importance for proper management of public affairs. For this, the three areas (PEs) were selected in the basin, quote: east, middle course and mouth of the river, for the application of indicators of environmental fragility of nature system. The basin was identified erosion, negative interactions of drainage systems with domestic wastewater, solid waste, among others. The General Indices Fragility (IGFs) were found 57, 49 and 72 respectively to the east, middle course and river estuary, featuring high grade fragility under the environmental aspect, ranging from strong to very strong. We conclude that the use of indicators of fragility is extremely importance to public administration, particularly as a tool for identifying intervening factors and fragility of urban stormwater drainage systems.
\end{abstract}

Keywords: Urban drainage; environmental assessment; environmental perception. 


\section{INTRODUÇÃO}

Os problemas decorrentes da urbanização desordenada são devido à inexistência de políticas de desenvolvimento urbano, como os planos diretores (RIBEIRO e ROOKE, 2010). Na confecção de planos diretores é de extrema importância abordar questões como drenagem pluvial urbana, pois a maioria das cidades brasileiras sofre com os efeitos danosos das chuvas intensas (TUCCI, 2007).

Para Porto et al. (1993) a obtenção de soluções adequadas para a drenagem pluvial urbana necessitam de metodologia que se adeque às peculiaridades sociais, institucionais e ambientais do local. Não tratando os sistemas de drenagem apenas como uma parte agregada ao ambiente urbano, mas sim combinado com outros sistemas, como: Planos Diretores de Desenvolvimento Urbano (PDDU) e Planos Diretores de Recursos Hídricos (SILVA et al., 2004).

Os sistemas de drenagem são dispositivos para prevenir inundações, alagamentos, erosões, e assoreamentos, principalmente nas margens de cursos d'água e em áreas mais baixas onde a população está mais sujeita a alagamentos e inundações (MOTA, 2008).

$\mathrm{O}$ uso de indicadores constitui-se como instrumento de grande relevância para o adequado gerenciamento de questões públicas, sobretudo na obtenção de diagnósticos e para a realização de monitoramentos ambientais. Como ressaltado por Kemerich et al. (2013) que para a gestão de bacias hidrográficas é de fundamental importância o conhecimento dos indicadores de fragilidade ou ainda de sustentabilidade, na caracterização da dinâmica dos problemas ambientais que existem em zonas de interesse.

Neste contexto, o objetivo deste estudo é utilizar Indicadores de Fragilidade do Sistema (IFS) de natureza ambiental e aplicá-los na bacia hidrográfica do rio Cintra em Montes Claros-MG, com intuito de notar os fatores que interferem no sistema de drenagem pluvial urbano e identificar o grau de fragilidade da bacia.

\section{METODOLOGIA}

\section{Área de estudo}

A bacia hidrográfica do rio Cintra (Figura 01) localiza-se no município de Montes Claros na mesorregião Norte do estado de Minas Gerais. A cidade possui 361.915 habitantes de acordo com o censo demográfico de 2010 e extensão territorial de 3.568,941 km²(IBGE, 2010). Apresenta clima $\mathrm{Aw}$ - tropical semi-úmido de acordo com Köppen, temperatura média anual de $24^{\circ} \mathrm{C}$, com período chuvoso concentrado entre os meses de outubro a março e o período seco entre os meses de abril a setembro (MOREIRA et al., 2013).

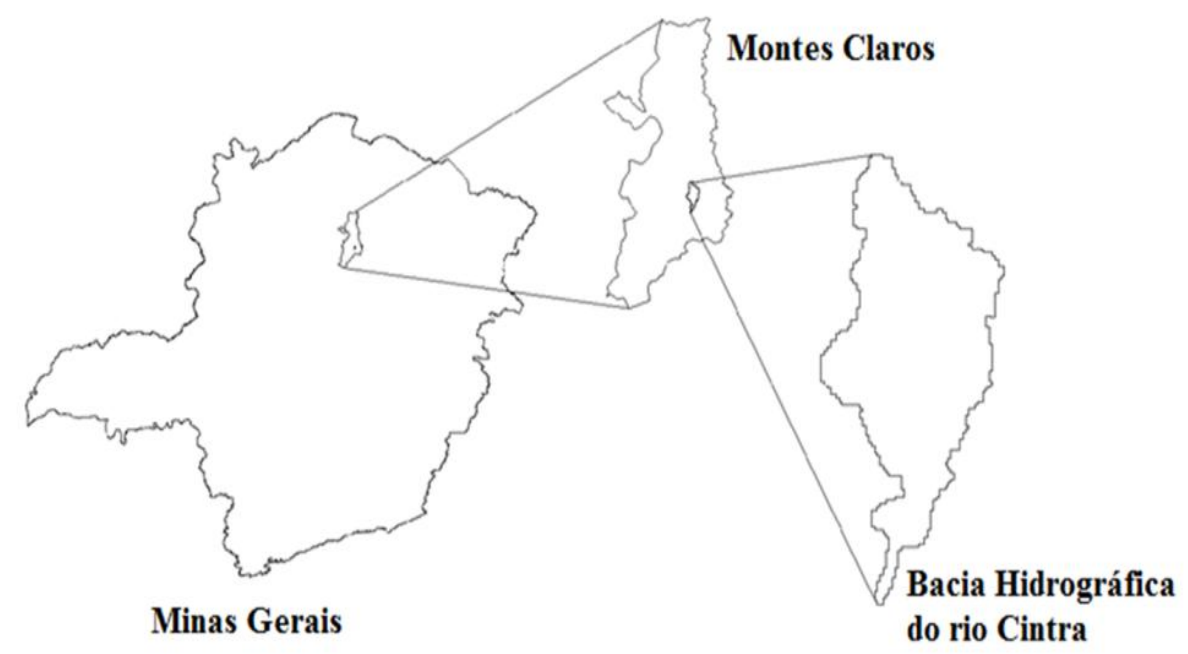

Figura 01. Localização da bacia hidrográfica do rio Cintra. 
A bacia do rio Cintra situa-se dentro do perímetro urbano de Montes Claros-MG, englobando, dentre outros, os seguintes bairros: Santa Rita I e II, Cintra, Planalto, JK, Delfino Magalhães, Carmelo, Santa Lúcia e Alcides Rabelo (SANTOS JÚNIOR, 2013).

\section{Bases metodológicas}

Este estudo baseou-se no trabalho realizado por Silva et al. (2004) que confeccionou uma metodologia que adiciona componentes socioambientais e institucionais na elaboração de planos de drenagem urbana de águas pluviais ao plano de saneamento do município de Alagoinhas-BA, o que permite um enfoque ambiental aos problemas de drenagem. Esta metodologia foi utilizada, adaptada e aplicada por Steiner (2011) e Santos Júnior (2013) em estudos focados em bacias hidrográficas urbanas. A metodologia proposta por estes autores visa, a princípio, a aquisição de dados, por eles denominados de Pontos de Estudo (PEs) por meio de visitas in loco, com intuito de obter e estes pontos e aplicar sobre eles os Indicadores de Fragilidade do Sistema (IFSs).

Os IFS são de natureza tecnológica, ambiental e institucional. Para fins desta pesquisa, foram aplicados somente os IFSs de natureza ambiental na bacia do rio Cintra e para isto, foram tomados três PEs na bacia do rio, um na nascente, um no médio curso do rio e outro na foz (Figura 02).

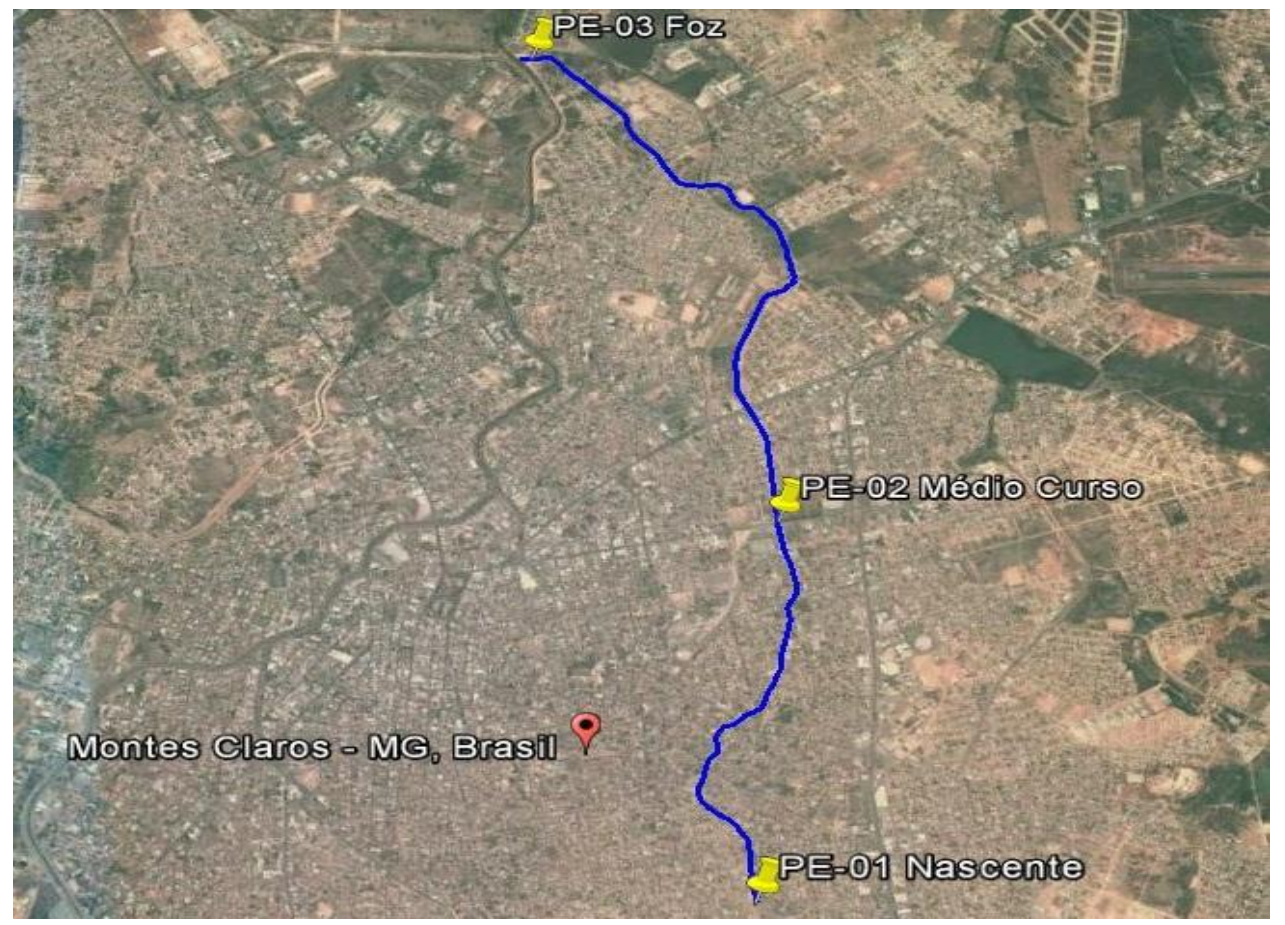

Figura 02 - Pontos de Estudo - PEs-01,02 e 03.

A Tabela 01 abaixo apresenta os fatores de natureza ambiental que interferem/afetam o sistema de drenagem e como foram abordados neste estudo.

Os IFSs de natureza ambiental de acordo com Silva et al. (2004) adaptado por Steiner (2011) e Santos Júnior (2013) são:

- Degradação física dos terrenos: consideram-se terrenos baldios e áreas com maiores declividade, as quais facilitem a produção de sedimento.

- Favorecimento da produção de sedimentos: consideram-se locais próximos a áreas verdes, terrenos baldios, áreas com maiores declividades, ou seja, fatores que produzem maior quantidade de sedimentos.

- Ocorrência de alagamento: áreas onde ocorrem alagamentos.

- Contribuição para alagamento de outro PE

- Deposição de resíduos gerais nas vias públicas: descarte de todos os tipos de resíduos em locais públicos. 
Assoreamento do corpo receptor: processos ocasionados pelo acúmulo de resíduos, entulho e outros detritos no fundo dos rios.

Interferências inadequadas: do sistema de drenagem com lixo, circulação de pedestres e veículos.

TABELA 01 - Fatores intervenientes no sistema de drenagem.

\begin{tabular}{|c|c|c|}
\hline Natureza & Fatores & Abordagem \\
\hline \multirow{13}{*}{ Ambiental } & Arranjo do traçado & $\begin{array}{l}\text { *Interação com } \text { topografia } \\
\text { respeito ao sistema natural de } \\
\text { drenagem }\end{array}$ \\
\hline & Usos do solo & $\begin{array}{l}\text { *Nível de impermeabilização } \\
\text { dos terrenos }\end{array}$ \\
\hline & & *Erodibilidade dos terrenos \\
\hline & & $\begin{array}{l}\text { *Ocupação marginal dos } \\
\text { corpos interceptores }\end{array}$ \\
\hline & Padrões de conforto das vias & ${ }^{*}$ De pedestres \\
\hline & & $\begin{array}{l}\text { *De grande fluxo de veículos e } \\
\text { de pedestres }\end{array}$ \\
\hline & & $\begin{array}{l}{ }^{*} \text { De grande fluxo de veículos e } \\
\text { baixo fluxo de pedestres }\end{array}$ \\
\hline & & *De médio movimento \\
\hline & & *De acesso local \\
\hline & $\begin{array}{l}\text { Interação com demais } \\
\text { equipamentos de saneamento }\end{array}$ & $\begin{array}{l}\text { *Lançamento de efluentes } \\
\text { domésticos na rede }\end{array}$ \\
\hline & & $\begin{array}{l}\text { *Lançamento de outros } \\
\text { efluentes na rede }\end{array}$ \\
\hline & & $\begin{array}{l}\text { *Deposição de lixo nas galerias } \\
\text { e canais }\end{array}$ \\
\hline & & $\begin{array}{l}\text { *Dispersão de sedimentos nas } \\
\text { vias }\end{array}$ \\
\hline
\end{tabular}

Fonte: Silva et al. (2004)

Foram adotados se seguintes valores fixados por Santos Júnior (2013) para a manifestação dos indicadores de fragilidade, conforme a Tabela 02 abaixo.

Tabela 02 - Valores para avaliação da manifestação dos indicadores.

\begin{tabular}{cc}
\hline Valores & Manifestação do indicador \\
\hline 0 & Indicador inexistente no PE \\
\hline 1 & Presente, sem agravante (100\%) \\
\hline 2 & Pouco agravante (75\%) \\
\hline 3 & Média (50\%) \\
\hline 4 & Musente, muito agravante (0\%) \\
\hline 5 &
\end{tabular}

Fonte: Santos Júnior (2013) 
De posse destes valores, foi necessário obter o Índice Geral de Fragilidade (IGF) que se deu pela soma dos valores dos indicadores nos PEs e, de acordo com Silva et al. (2004) quanto mais elevado for o IGF, maior será a fragilidade dos PEs.

Os valores do IGF variam entre 0 a 80 e foram divididos em graus, com os respectivos intervalos de fragilidade, a citar: muito baixa, baixa, média, forte e muito forte, conforme a Tabela 03 a seguir.

Tabela 03 - Graus e intervalos de Fragilidade

\begin{tabular}{cc}
\hline Graus & Intervalos (IGF) \\
\hline Muito Baixa & $0-16$ \\
\hline Baixa & $16-32$ \\
\hline Média & $32-48$ \\
\hline Forte & $48-64$ \\
\hline Muito Forte & $64-80$ \\
\hline
\end{tabular}

\section{RESULTADOS}

A visita in loco iniciou-se na nascente do rio passando pelo ponto de médio curso em direção à foz, onde foram tomados e avaliados a manifestação dos IFSs de natureza ambiental. Percebendose ao longo do rio: erosão, assoreamento, grande quantidade de resíduos sólidos, o lançamento de efluentes domésticos entre outros fatores que interferem de forma negativa a drenagem pluvial da bacia do rio Cintra.

No PE-01 notou-se grande presença de materiais sólidos em suspensão e o lançamento de efluente doméstico (Figura 03).

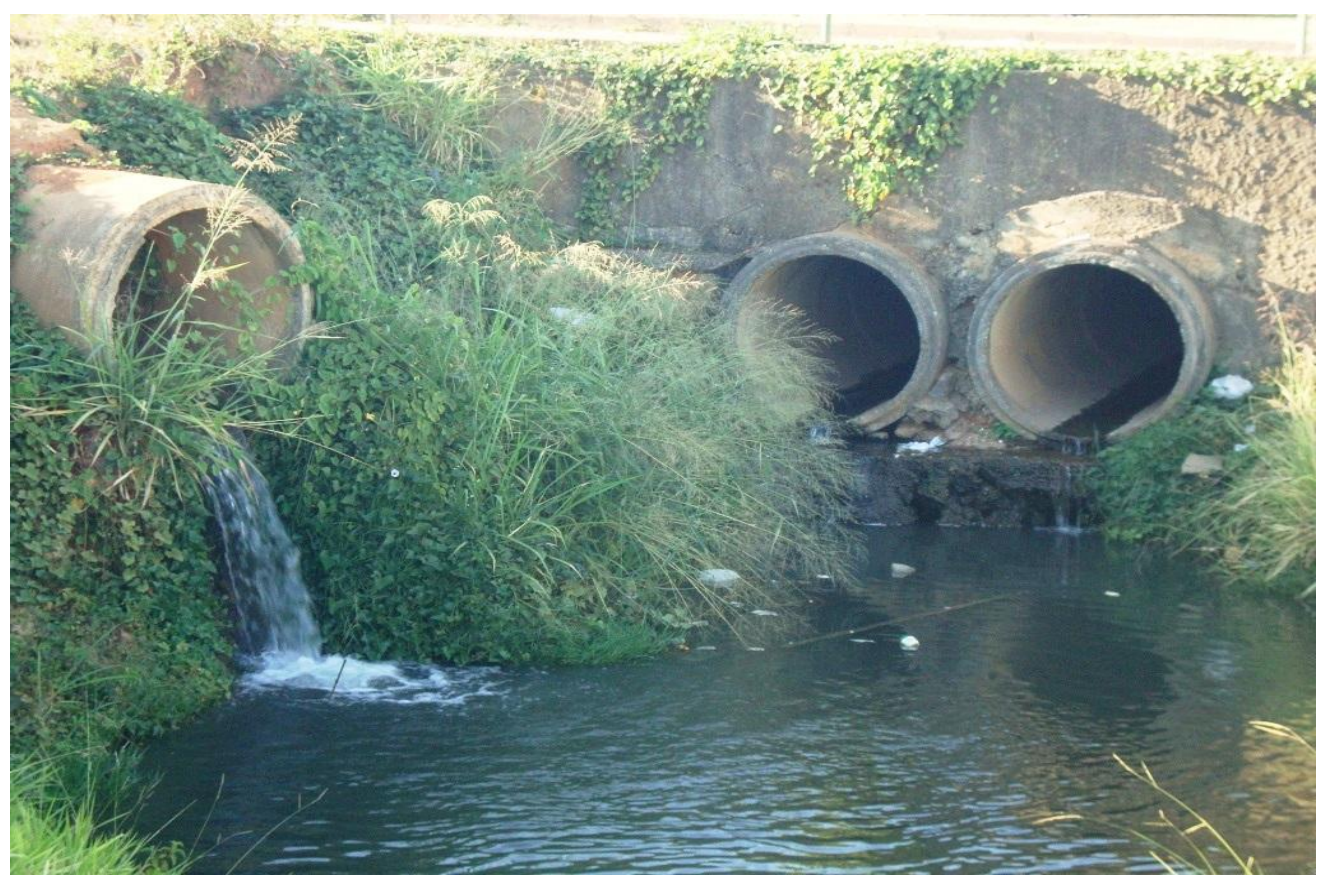

Figura 03 - Nascente do rio Cintra em Montes Claros - MG.

A Figura 04 abaixo expõe algumas questões ambientais, como: a interação da população com o rio pela presença de construções e o assoreamento do corpo hídrico. 


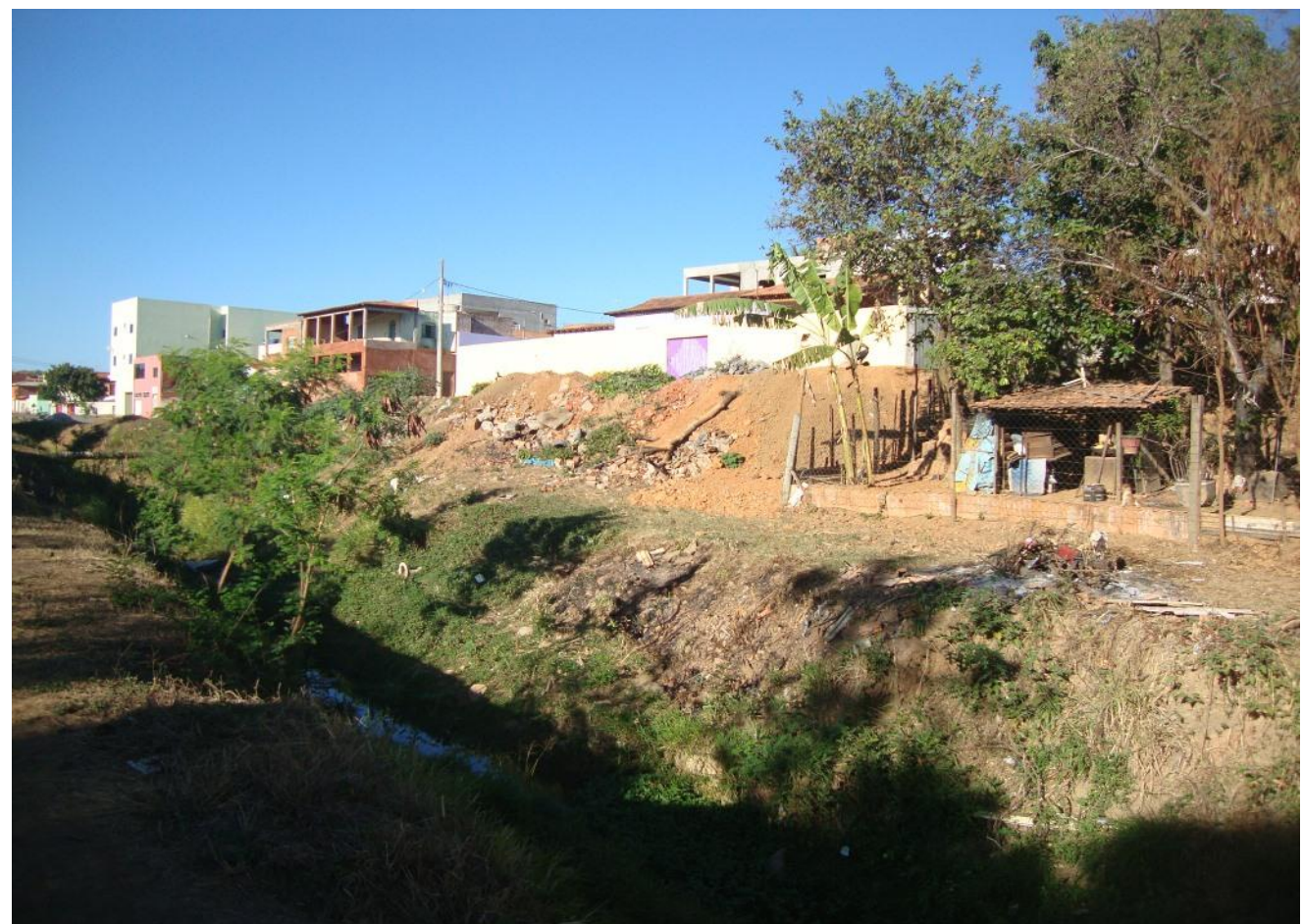

Figura 04 - Presença de construções no leito do rio Cintra e assoreamento.

No PE-02 nota-se a falta de pavimentação, a interação com vias públicas, resíduos sólidos no corpo receptor e a poluição do rio.

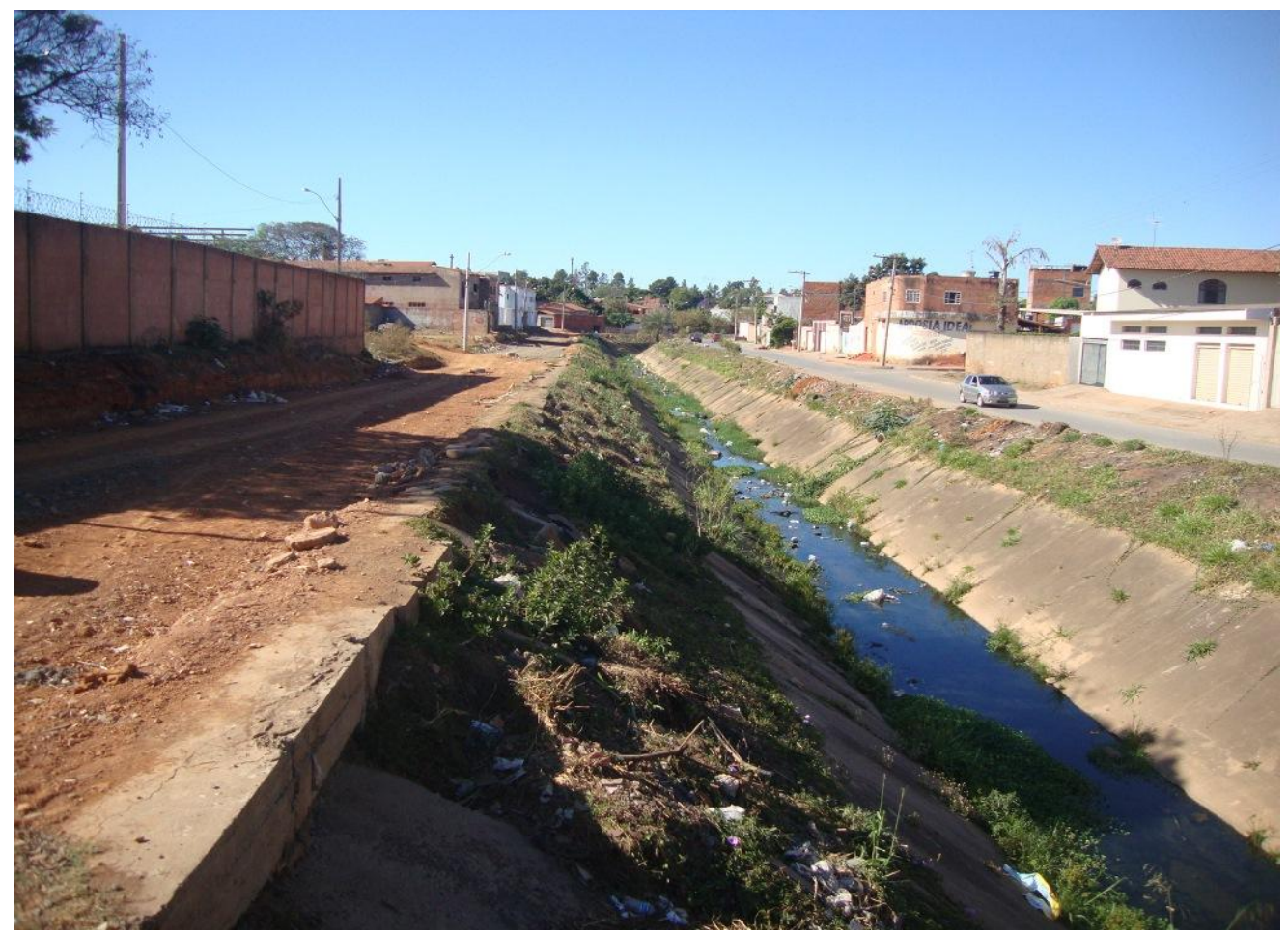

Figura 05 - Presença de material sólido nas vias sem pavimento.

No PE-03, na foz do rio Cintra é forte a interação do curso hídrico com efluente doméstico e resíduos sólidos. A forma deste canal contribui para elevação das vazões de cheias. 


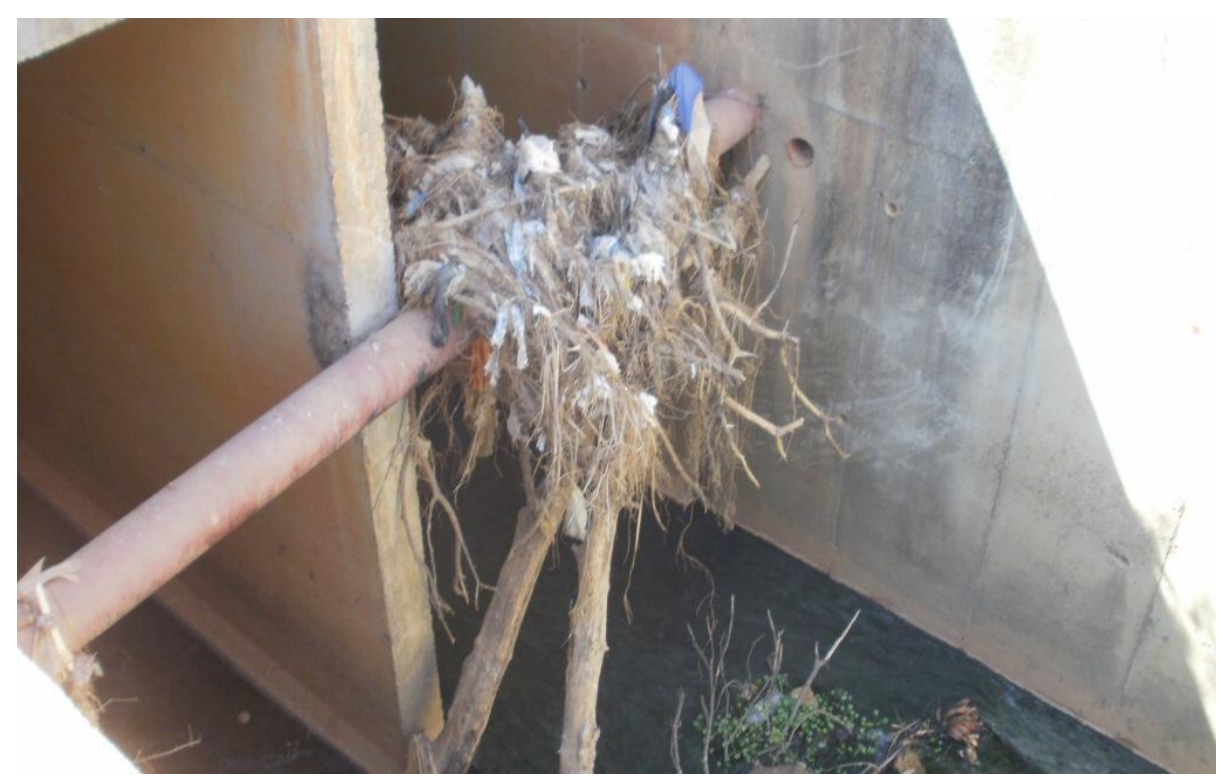

Figura 06 - Resíduos sólidos presentes em uma tubulação do canal na foz do rio Cintra.

A Tabela 04 abaixo apresenta os valores de atribuídos aos IFS de natureza ambiental e o Índice Geral de Fragilidade Ambiental de cada PE da bacia.

TABELA 04 - Índice de Fragilidade no Sistema (IFS) no Ponto de Estudo 01 (PE-01).

\begin{tabular}{|c|c|c|c|c|}
\hline $\begin{array}{l}\text { Natureza do } \\
\text { Indicador }\end{array}$ & Indicadores & Nota PE-01 & Nota PE-02 & Nota PE-03 \\
\hline \multirow{16}{*}{ AMBIENTAL } & Ocorrência de alagamentos & 2 & 1 & 5 \\
\hline & Prejuízos materiais & 2 & 1 & 4 \\
\hline & Risco de vidas humanas & 2 & 1 & 2 \\
\hline & $\begin{array}{l}\text { Interferência negativa na rede natural de } \\
\text { drenagem }\end{array}$ & 1 & 2 & 5 \\
\hline & Erosão nos terrenos da bacia & 5 & 5 & 5 \\
\hline & $\begin{array}{l}\text { Arraste de material das vias sem } \\
\text { pavimento }\end{array}$ & 3 & 2 & 5 \\
\hline & Deposição de sedimentos em vias públicas & 5 & 3 & 5 \\
\hline & Interação inadequada com esgotos & 4 & 5 & 5 \\
\hline & Interação inadequada com lixo & 5 & 5 & 5 \\
\hline & Elevação das vazões de cheias & 4 & 4 & 5 \\
\hline & Limitação das áreas de inundação & 4 & 4 & 4 \\
\hline & Interferência no trânsito de veículos & 1 & 1 & 3 \\
\hline & Interferência na circulação de pedestres & 5 & 4 & 4 \\
\hline & Contaminação do corpo receptor & 5 & 5 & 5 \\
\hline & Contato da população com águas poluídas & 4 & 1 & 5 \\
\hline & Assoreamento do corpo receptor & 5 & 5 & 5 \\
\hline \multicolumn{2}{|c|}{ Índice de Geral de fragilidade (IGF) - Ambiental } & 57 & 49 & 72 \\
\hline
\end{tabular}


A Figura 07 abaixo mostra um gráfico com os valores do IGF encontrados em cada PEs da bacia hidrográfica do rio Cintra.

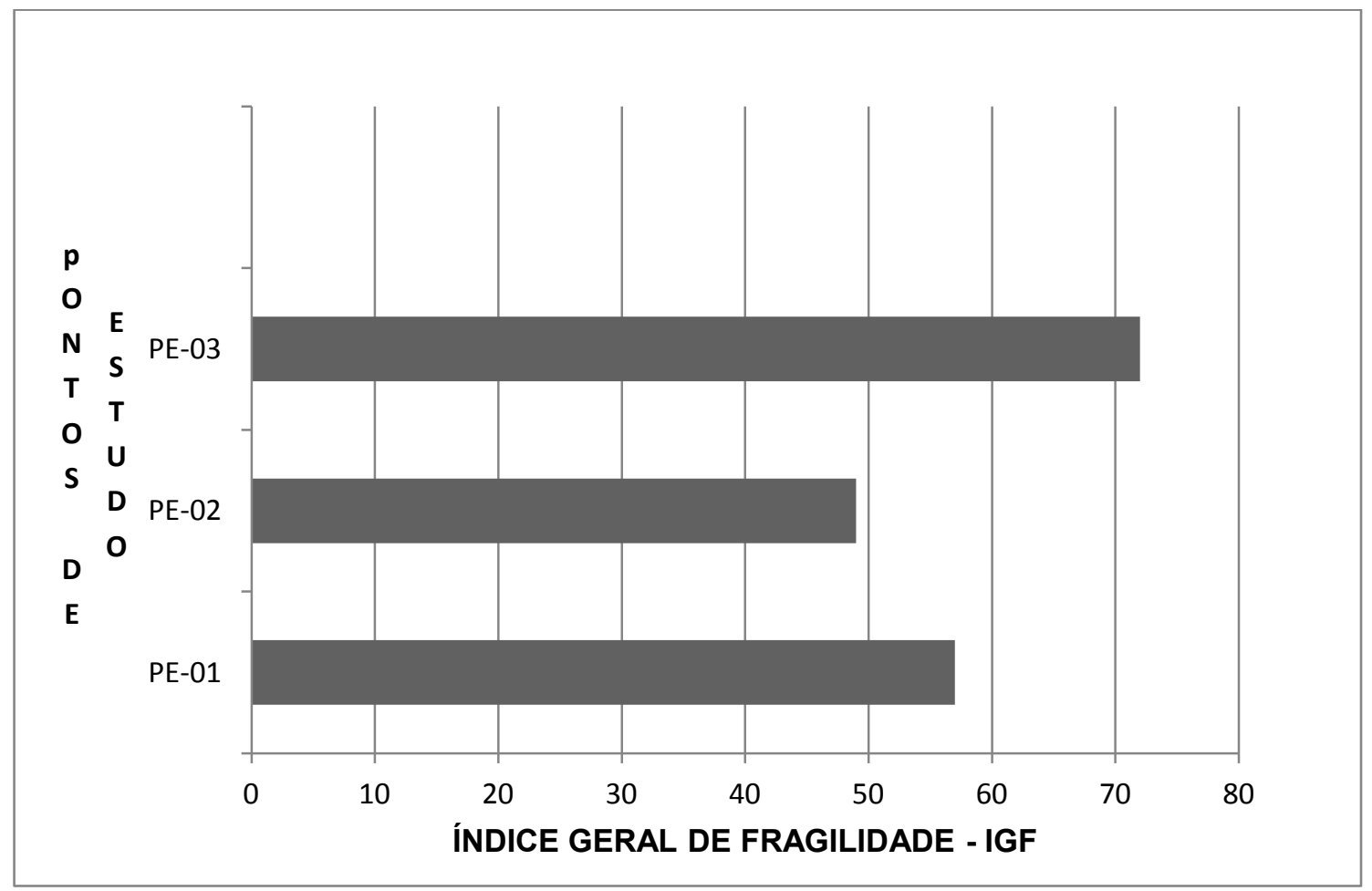

Figura 07 - Graus e os IGF dos Pontos de Estudo

Os graus de fragilidade do sistema de drenagem na bacia hidrográfica do rio Cintra variaram entre Forte nos dois primeiros PEs a Muito forte no terceiro PE.

\section{CONCLUSÃO}

O uso de indicadores de fragilidade serve-se de ferramenta auxiliar na gestão pública, permitindo a análise de questões relacionadas à drenagem pluvial urbana.

Com a metodologia aplicada, foi possível identificar os fatores de natureza ambiental que interferem no sistema de drenagem pluvial na bacia. Percebeu-se nos três Pontos de Estudos, a presença processos erosivos, resíduos sólidos nas margens do rio, grande interação dos sistemas de drenagem com vias públicas, a passagem de pedestres, veículos, efluentes domésticos, dentre outros.

Os graus de fragilidade na bacia são altos, variaram de forte a muito forte, caracterizando, sob o aspecto ambiental, que a bacia hidrográfica do rio Cintra apresenta grande fragilidade em seus sistemas de drenagem.

\section{REFERÊNCIAS}

IBGE - Instituto Brasileiro de Geografia e Estatística. Censo demográfico: sinopse - Minas Gerais, 2010.

KEMERICH, P. D. da C. et al. Avaliação da Sustentabilidade Ambiental em bacias hidrográficas mediante a aplicação do modelo P-E-R. Rev. Elet. em Gestão, Educação e Tecnologia Ambiental, v. 10, n. 10, 2013.

MOREIRA, A. A. et al. Análise do Comportamento Espectral de Fitofisionomias no Parque Estadual Lapa Grande por meio de dados MODIS. Revista Brasileira de Geografia Física, v. 6, n. 6, 2013. 
MOTA, S. Gestão ambiental de recursos hídricos. 3. ed. Rio de Janeiro: ABES, 2008.

PORTO, R.; ZAHEL, F. K; TUCCI, C.; BIDONE, F. Drenagem Urbana. In: Hidrologia: ciência e aplicação. TUCCI, C. E. M. (org.). Porto Alegre: Ed. da Universidade, ABRH, EDUSP, 1993.

RIBEIRO, J. W.; ROOKE, J. M. S. Saneamento básico e sua relação com o meio ambiente e a saúde pública. 2010. 36 f. Trabalho de Conclusão de Curso (Especialização em Análise Ambiental) - Universidade Federal de Juiz de Fora - UFJF, Juiz de Fora, 2010.

SILVA, B. J. da; PEREIRA, O. S.; ASSIS, W. A. V. de; MORAIS, L. R. S. O componente drenagem urbana no plano municipal de saneamento ambiental de Alagoinhas, Bahia. Disponível em: <www.semasa.sp.gov.br/ admin/biblioteca/docs/pdf/35Assemae126.pdf>. Acesso em: 10 maio 2014.

SANTOS JÚNIOR, V. J. dos. Avaliação da drenagem pluvial da bacia hidrográfica do córrego Cintra em Montes Claros/MG. 2013. 84 f. Trabalho de Conclusão de Curso (Engenharia Ambiental) - Faculdade de Ciências Exatas e Tecnológicas Santo Agostinho - FACET, Montes Claros, 2013.

SILVA, B. J. da. et al. O componente drenagem urbana no plano municipal de saneamento de Alagoinhas, Bahia.2004. Disponível em: <www.semasa.sp.gov.br/admin/biblioteca/docs/pdf/35Assemae126.pdf $\neg$ >. Acesso em: 15 maio 2014.

STEINER, L. Avaliação do sistema de drenagem pluvial urbana com aplicação do índice de fragilidade. Estudo de caso: microbacia do Rio Criciúma, SC. 2011. 106 f. Trabalho de Conclusão de Curso (Engenharia Ambiental) - Universidade do Extremo Sul Catarinense - UNESC, Criciúma, 2011.

TUCCI, C. E. M. Inundações urbanas. Porto Alegre: ABRH/RHAMA, 2007. 